\title{
Attitude of the medical personnel of a pediatrics department towards patient death
}

\author{
Luz María Sánchez-Sánchez, Edreí Daniel López-Córdova and Pedro Siller-Gómez \\ Instituto Mexicano del Seguro Social, Centro Médico Nacional del Noreste, Specialty Hospital 25, Monterrey, Nuevo León, Mexico
}

\begin{abstract}
Introduction: Tertiary care hospitals' physicians require high emotional competence, since they are faced with the demands of terminally ill patients and their families. Objective: to assess the attitude of physicians of a pediatrics department towards patient death. Method: Pediatrics staff and resident physicians anonymously answered the Attitudes Towards Death (ATD) questionnaire. Absolute frequencies, percentages, means, standard deviations, Student's $t$-test and the chi-square test were used. Statistical significance was considered with $p<0.05$. Results: The questionnaire was answered by 38 physicians, 26 (68.4\%) were residents and 12 (37.6\%) staff physicians; 15 (39.4\%) were males and 23 (60.6\%) females. Four residents (15.4\%) had a positive attitude versus 2 staff physicians (16.7\%) $(p=0.920)$. Statistical significance was found in items $1(69.2 \%$ of residents versus $100 \%$ of staff physicians, $p=0.03$ ), 16 (23\% of residents versus $100 \%$ of staff physicians, $p=0.001)$ and 19 (92.3\% of residents versus $58.3 \%$ of staff physicians, $p=0.01)$, corresponding to the avoidance, acceptance and professional perspective dimensions. Conclusion: Less than $20 \%$ of pediatric physicians have a positive attitude towards death. Most didn't value death as a passage or transition to a better life, or as a solution to life's problems.
\end{abstract}

KEY WORDS: Physician's attitude. Palliative care. Attitude towards death questionnaire.

\section{Introduction}

In current society, children are expected to outlive their parents. However, children also suffer chronic-degenerative diseases that lead to a terminal status that inexorably advances towards death.

A life-limiting illness is defined as a situation where premature death is expectable, although not necessarily imminent. A life-threatening illness is that which has a high probability of early death, but where there is also possibility of survival until adulthood. ${ }^{1}$

Four groups of situations have been identified in children:

- Group 1. Life threatening situations where curative treatment can be viable, but it also can fail (e.g., infections, cancer, heart, liver or kidney organ failure).

- Group 2. Diseases that require long periods of intensive treatment aimed at prolonging life, but where early death is still possible (e.g., cystic fibrosis, HIV/AIDS, cardiovascular conditions, extreme prematurity).

- Group 3. Progressive diseases with no curative options, where treatment is palliative since diagnosis (e.g., neuromuscular or neurodegenerative disorders, progressive metabolic disorders, chromosomal anomalies, advanced metastatic cancer at diagnosis).

- Group 4. Non-progressive, irreversible situations with severe disability that entail extreme vulnerability for suffering health complications (e.g., severe cerebral palsy, genetic disorders, congenital malformation, prematurity, brain or bone marrow lesions). ${ }^{2,3}$

Death is a true biological, psychosocial and cultural process rather than an instantaneous phenomenon. In modern times, there is a tendency towards concealment, avoidance of the subject of death, by means of
Correspondence: Luz María Sánchez-Sánchez E-mail: luzsanchez68@ hotmail.com
Date of reception: 22-01-2016

Date of acceptance: 30-04-2016

DOI://dx.doi.org/10.24875/GMM.M18000123
Gac Med Mex. 2018;154:111-118

Contents available at PubMed www.gacetamedicademexico.com 
rigid social censorship that even involves misleading the dying patient, turning him/her into an isolated being, full of desperation and with insufficient care.

Lack of time, lack of curricular training in communication techniques, self-susceptibility towards the representation of death and insecurity are factors originating in healthcare personnel that affect and make the dying patient more vulnerable. The subject of death remains a taboo, with its specific characteristics. ${ }^{4}$

Even when illness and death constitute real possibilities of human existence, talking about the subject is often avoided. Contemporary social customs facilitate this evasive attitude. The idea of ceasing to exist is rejected, and death becomes a foreign, feared act. The attitude an individual has in the face of death can even influence on his/her behavior and relate to that person's problems of. Death has become an expression of fear, of failure in the search of happiness and success. Paradoxically, society, which ultimately is mortal, rejects death. In fact, although essential to human existence, death has become an absurd, suffered in ignorance and passivity, in a lack of solidarity and abandonment with regard to dying, deceased and survivor human beings. ${ }^{5}$

Former family member deaths have been turning into concealed deaths. People don't dye at home anymore, but at the hospital, alone. Forcedly happy life tries to drive away any idea of death, and appearances of "always being alive" predominate. The subject is masked, children are told about death by means of euphemisms; mourning is increasingly carried out in intimacy and pain is barely shared.

Professionals at hospitals tend to conceive death as a failure instead of accepting it as a natural, necessary phenomenon. Every day, the idea of dying without noticing it is more desirable, but dying without others noticing it is also convenient. Although there are differences in several countries, and even within a single country between different regions, most people who fall chronically ill are going to die at the hospital. Almost nobody dies at home anymore, surrounded by his/her beloved ones. Modern man has increasingly been losing his right to be the protagonist of the act of dying, which is turning into an increasingly more "technical" process, into something that has to be quickly forgotten; thus, not only the quality of death is affected, but also the quality of life of final moments. It is not casual that the World Health Organization (WHO) promotes the idea that the patient should die at home, surrounded by his/her dearest objects, in a calm atmosphere, accompanied by his/ her family and loved ones, respecting his/her rights and will, after having received the benefits of palliative care programs for a certain time..$^{6-9}$

Sometimes, specialists underestimate the child's understanding about his/her illness, about death and other issues related to spirituality. Children can understand the concept of death as a state of transition at about 3 years of age; they can start having the sense of the possibility of personal mortality at 8 or 9 years of age. Spirituality and religiousness or piety can go separately. Even without a religious setting, children possess a spiritual life. ${ }^{10,11}$

Myra Bluebond-Langner first described the "mutual pretense" that often doesn't let children and their parents communicate about death and the fact of dying. ${ }^{12}$ In Sweden, Kreicberg et al. recently published a retrospective study about parents who had lost a child to cancer. Of the 147 who referred having spoken with their child about death, no one did regret it, in comparison with $27 \%$ of the 258 parents who didn't talk about it. Among the parents who felt their child was aware of his/her imminent death, the probability of regret for not having talked about it was higher. The parents who did not speak about death had a higher level of anxiety during follow-up. ${ }^{13}$

Loss of a child is one of the greatest stress factors in life. Parents who lose a child are at risk of suffering complex grieving reactions, as well as possible death from natural or unnatural causes. The defensive reactions of families of children and adolescents who face a chronic and terminal illness include guilt, anxious overprotection, rejection, denial of the disease, and dependence and negation or contempt for doctors. Mothers can develop major depression, since death of a child is hard to accept. ${ }^{14}$

For health professionals, in particular for doctors, the topic of deaths involves a complex analysis, since it encompasses their entire attitude towards the patient; it is difficult for them to maintain a serene and mature attitude when dealing with death. When it occurs, they immediately try to feel well, an attitude that reveals a form of concealment, a defense mechanism against pain. Health professionals, especially doctors, are supposed to be most comprehensively educated by, for and against death, seen as a biological reality, a human phenomenon and a cultural value. However, it is not always like this, which often reflects on deficient care of incurable patients..$^{15-18}$

First, there is a training deficit, since they are not taught what to do with incurable patients, and this is not compensated with the good will to help, but gives 
rise to a defensive situation by the professional, to $\mathrm{him} /$ her responding to anxiety with inadequate defense mechanisms: anger, negative attitudes, etc. Second, for health professionals, especially for physicians, death constitutes a feeling of professional failure; they are taught to save lives, and although they know death is unavoidable, they tend to feel guilty for not being able to cure their patients. Thirdly, the confrontation with patient death generates anxiety for their own death, since they are also human beings, and in scenarios like this, prejudices and beliefs, anxieties and each one's personal history come to the surface. ${ }^{19}$

Every health professional should have an interest in analyzing and understanding the different components of his/her discomfort: gaining awareness of the hidden reasons that urge him/her to flee when confronted with such situations would enable him/her to rectify his/her attitude and be more comfortable in similar circumstances. Anyway, most times, the terminally ill patient and his/her family are under great impact and generate a highly emotionally charged environment that health providers have to know how to deal with; the health professional should be prepared and be trained for it, learn that death is something natural. When he/she is able to accept it like this, he/she will be dedicated to provide care and comfort to the patient until the end and without a feeling of failure. ${ }^{20-22}$ The physician's attitude is vital to adequate patient care, and it largely determines their attitude in the face of the proximity of their death.

The development of adequate attitudes towards death or a significant change of attitudes towards it, a movement of understanding and respect regarding the circumstances of death, where multidisciplinary teams approach patients and their families is clearly needed.

\section{Method}

Staff physicians and pediatrics residents from the Pediatrics Department of Specialty Hospital 25, Centro Médico Nacional del Noreste, Mexican Institute of Social Security, in Monterrey, Nuevo León, were anonymously applied the Attitudes Toward Death (ATD) questionnaire, which obtained a Cronbach's alpha-value of 0.713 when previously assessed.

The ATD questionnaire consists of 33 items, with two-choice answers (agreement or disagreement), which can add up to a total of 33 to 165 points; 141 or more points corresponds to a positive attitude towards death, while lower scores indicate a negative attitude. For interpretation, it is divided in 6 domains that correspond to different attitudes towards death: avoidance, acceptance, fear, based on beliefs that death is a passage or transition, founded on the conception of death is an exit or solution and another that involves professional perspective (appendix 1). ${ }^{20,22}$ Each domain was separately assessed between the groups of health professionals of the pediatrics department.

The informed consent warranted participants' anonymity, given that attitude towards an issue implies a personal posture, and it is desirable for participants to feel completely free to express it without being identified.

For analysis, absolute frequencies and percentages were used, as well as means or medians with standard deviations or ranges. To compare the scores obtained between staff physicians and residents, Student's t-test or Mann-Whitney U-test were used. The chi-square test or Fisher's exact test were used for qualitative variables. Statistical significance was considered at $p<0.05$.

The present study complies with the considerations formulated in the Declaration of Helsinki and its Tokyo 1975, Venice 1983 and Hong Kong 1989 revisions; in addition, it adheres to the considerations formulated in research for health of the General Statute of Health of the Mexican United States and to the scientific research commission operative instructions and the Mexican Institute of Social Security local research committees.

\section{Results}

Thirty-eight physicians agreed to answer the 33 -item ATD questionnaire. Out of total surveyed subjects, 26 were resident physicians $(68.4 \%)$ and 12 were staff physicians (31.6\%); 15 were males (39.4\%) and 23 were females (60.6\%). Residents' age was $28 \pm$ 1.6 years, whereas for staff physicians it was $44.9 \pm$ 10.3 years. Seniority was $2.8 \pm 1.6$ years for residents and $15.2 \pm 8.5$ years for staff physicians $(p=0.001)$.

The questionnaire total score was $120 \pm 16.4$ for residents and $133 \pm 14.4$ for staff physicians $(p=0.05$ ). As regards the questionnaire dimensions, avoidance when faced with death was $21 \pm 4.7$ points for resident physicians in comparison with $25 \pm 2.0$ in staff physicians ( $p=0.086)$; for acceptance, $21 \pm 5.6$ points were found in residents and $23 \pm 4.5$ in staff physicians ( $p$ $=0.090$ ); as for fear of death, $21 \pm 6.1$ points were obtained by residents and $21 \pm 6.9$ by staff physicians 
$(p=0.908)$. With regard to those who believe that death is a passage, the obtained scores were $17 \pm 7.5$ for residents and $21 \pm 5.7$ for staff physicians ( $p=0.304$ ). Among those who see death as an exit, the score was $21 \pm 3.03$ for residents and $21 \pm 4$ in staff physicians $(p=0.980)$; when professional perspective was assessed, a score of $28 \pm 4.07$ was obtained by resident physicians and $28 \pm 4.55$ by staff physicians ( $p=0.116)$. An ATD questionnaire total score higher than 141 is regarded as a positive attitude towards death; 4 residents $(15.4 \%)$ had a positive attitude in comparison with 2 staff physicians $(16.7 \%)(p=0.920)($ Table 1).

In table 2, items were grouped by dimension and individually analyzed in staff physicians and residents. Significant difference was found in item 1 (thinking about death is a waste of time), which corresponds to the avoidance dimension: 18 residents $(69.2 \%)$ answered being in disagreement in comparison with all 12 staff physicians $(100.0 \%)(p=0.03)$. In item 16 (I have thought of death as something unavoidable), which corresponds to death acceptance, 6 residents (23\%) agreed, in comparison with 12 staff physicians $(100 \%)(p=0.00)$. On item 19 (when I look after a terminal patient, I use to think about my own death), which belongs to the professional perspective dimension, 24 residents (92.3\%) indicated disagreement, in comparison with 7 staff physicians $(58.3 \%)(p=0.01)$. There were no statistically significant differences for the remaining items of the questionnaire.

Ambiguity of answers was noticed with similar percentages of agreement and disagreement for item 7 (my life has more meaning because I accept the fact of my own death), which corresponds to acceptance. In the passage dimension, which is based on beliefs that death is a passage or transition to another life, there was more answer ambiguity, since agreement and disagreement percentages were similar in 4 of its 5 items. In the professional perspective dimension there was ambiguity in the answer to item 12 (I can't help thinking about my family when facing a patient who is going to die). Ambiguity was also observed in the answer to item 15 (I prefer dying than living without quality), which corresponds to the exit dimension, and to item 28 (I think with fear about the possibility of contracting a disease that drives me to death), which corresponds to the fear dimension.

\section{Discussion}

Death is not an instantaneous phenomenon, but
Table 1. Demographic characteristics and Attitude Toward Death Questionnaire scores obtained by 38 physicians*

\begin{tabular}{|c|c|c|c|}
\hline & $\begin{array}{l}\text { Residents } \\
(\mathrm{n}=26)\end{array}$ & $\begin{array}{c}\text { Staff } \\
(n=12)\end{array}$ & $p^{p}$ \\
\hline \multicolumn{4}{|l|}{ Gender } \\
\hline Male & $8(30.7 \%)$ & $7(58.3 \%)$ & 0.920 \\
\hline Female & $18(69.3 \%)$ & $5(41.6 \%)$ & $\frac{\swarrow}{\sigma}$ \\
\hline Age (years) & $28.1 \pm 1.6$ & $44.9 \pm 10.3$ & 0.001 \\
\hline Seniority (years) & $2.8 \pm 0.8$ & $15.2 \pm 8.5$ & 0.001 \\
\hline $\begin{array}{l}\text { Attitude towards } \\
\text { death }(\text { score })^{*}\end{array}$ & $120 \pm 16.4$ & $133 \pm 14.4$ & 0.050 \\
\hline \multicolumn{4}{|l|}{ Dimension (score) $)^{*}$} \\
\hline Avoidance & $21 \pm 4.7$ & $25 \pm 2.0$ & 0.086 \\
\hline Acceptance & $21 \pm 5.6$ & $23 \pm 4.5$ & 0.090 \\
\hline Fear & $21 \pm 6.1$ & $21 \pm 6.9$ & 0.908 \\
\hline Passage & $17 \pm 7.5$ & $21 \pm 5.7$ & 0.304 \\
\hline Exit & $21 \pm 3.0$ & $21 \pm 4.0$ & 0.980 \\
\hline Professional perspective & $28 \pm 4.0$ & $28 \pm 4.5$ & 0.116 \\
\hline \multicolumn{4}{|l|}{ Attitude towards death } \\
\hline Positive & $4(15.4 \%)$ & $2(16.7 \%)$ & 0.920 \\
\hline Negative & $22(84.6 \%)$ & $10(83.3 \%)$ & $\frac{\varsigma}{d}$ \\
\hline
\end{tabular}

"Department of Pediatrics, Specialty Hospital 25, Monterrey, Nuevo León.

Values expressed as mean \pm standard deviation or absolute frequencies (percentage).

Although disease and death are real possibilities of human existence, speaking about the subject is often avoided. Awareness of death is an essentially human characteristic; attitudes, beliefs, feelings and behaviors of man in the face of death, remain psychosocial phenomena that are culturally learnt and reinforced throughout life.

For health professionals, particularly for doctors, the subject of death involves a complex analysis, since it encompasses their entire attitude towards the patient; it is difficult maintaining a serene and mature attitude when dealing with death. When it occurs, they immediately try to feel well, which is a form of concealment, a defense mechanism against the pain it produces. They are supposed to be the most comprehensively trained professionals by, for and against death, seen as a biological reality, a human phenomenon and a cultural value. ${ }^{4}$

Mexican Institute of Social Security Specialty Hospital 25, in Monterrey, Nuevo León, provides medical care to patients coming from the northeastern zone of the country, offering care to children, most of them diagnosed with diseases that are chronic, disabling or catastrophic for life, and knowledge on having a positive attitude by health personnel is therefore essential in order to offer quality care. ${ }^{1}$

Numerous barriers to having a positive attitude towards death have been identified: insufficient financial resources for specialized pediatric care, limited 
Table 2. Results obtained for each item of the Attitude Toward Death Questionnaire by 38 physicians*

\begin{tabular}{|c|c|c|c|c|c|c|c|c|}
\hline \multirow[t]{2}{*}{ Item } & \multirow[t]{2}{*}{ Dimension } & & \multicolumn{2}{|c|}{ Residents $(n=26)$} & \multicolumn{2}{|c|}{ Staff $(n=12)$} & \multirow[b]{2}{*}{$+\infty$} & \multirow[t]{2}{*}{ p } \\
\hline & & & Agree & Disagree & Agree & Disagree & & \\
\hline 2 & Ac & $\begin{array}{l}\text { Acceptance of death helps me to have more } \\
\text { responsibility towards life. }\end{array}$ & $21(80.8 \%)$ & $5(19.2 \%)$ & $11(91.7 \%)$ & $1(8.3 \%)$ & 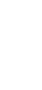 & 0.39 \\
\hline 7 & Ac & $\begin{array}{l}\text { My life has more meaning because I accept the fact } \\
\text { of my own death. }\end{array}$ & $14(53.8 \%)$ & $12(46.2 \%)$ & $8(66.7 \%)$ & $4(33.3 \%)$ & 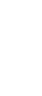 & 0.46 \\
\hline 16 & Ac & I have thought of my death as an unavoidable fact. & $6(23.1 \%)$ & $20(76.9 \%)$ & $12(100 \%)$ & - & (C) & 0.00 \\
\hline 23 & Ac & $\begin{array}{l}\text { Recognizing death as an unavoidable fact helps my } \\
\text { personal growth. }\end{array}$ & $18(69.2 \%)$ & $8(30.7 \%)$ & $9(75 \%)$ & $3(25 \%)$ & $\frac{\dot{c}}{\frac{1}{4}}$ & 0.70 \\
\hline 27 & $A c$ & I feel freer by accepting my death. & $16(61.5 \%)$ & $10(38.4 \%)$ & $11(91.6 \%)$ & $1(8.3 \%)$ & 을 & 0.06 \\
\hline 1 & Av & Thinking about death is a waste of time. & $8(30.8 \%)$ & $18(69.2 \%)$ & - & $12(100 \%)$ & (1) & 0.03 \\
\hline 8 & Av & $\begin{array}{l}\text { I consider deliberately thinking about my unavoidable } \\
\text { death to be morbid. }\end{array}$ & $23(88.5 \%)$ & $3(11.5 \%)$ & $9(75 \%)$ & $3(25 \%)$ & 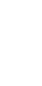 & 0.20 \\
\hline 17 & Av & I really prefer not thinking about death. & $9(34.6 \%)$ & $17(65.3 \%)$ & $2(16.6 \%)$ & $10(83.3 \%)$ & $\frac{0}{n}$ & 0.20 \\
\hline 22 & $A v$ & $\begin{array}{l}\text { I have thus far not thought about death as a real } \\
\text { possibility. }\end{array}$ & $6(23.1 \%)$ & $20(76.9 \%)$ & - & $12(100 \%)$ & $\frac{\varepsilon}{2}$ & 0.07 \\
\hline 32 & Av & $\begin{array}{l}\text { People should only think about death when they are } \\
\text { old. }\end{array}$ & $3(11.5 \%)$ & $23(88.4 \%)$ & 0 & $12(100 \%)$ & $\frac{1}{ \pm}$ & 0.22 \\
\hline 4 & $P$ & I think there is a better place in the afterlife. & $18(69.2 \%)$ & $8(30.8 \%)$ & $10(83.3 \%)$ & $2(16.7 \%)$ & $\stackrel{-}{\circ}$ & 0.36 \\
\hline 10 & $P$ & I think I will live after my death. & $16(61.5 \%)$ & $10(38.4 \%)$ & $8(66.6 \%)$ & $4(33.3 \%)$ & e & 0.76 \\
\hline 18 & $P$ & I see death as one step to eternity. & $16(61.5 \%)$ & $10(38.4 \%)$ & $11(91.6 \%)$ & $1(8.3 \%)$ & $\stackrel{+2}{\Perp}$ & 0.06 \\
\hline 25 & $P$ & I expect life after death with pleasure. & $11(42.3 \%)$ & $15(57.6 \%)$ & $6(50 \%)$ & $6(50 \%)$ & $\stackrel{\circ}{\frac{O}{t}}$ & 0.60 \\
\hline 29 & $P$ & After death I will find happiness. & $11(42.3 \%)$ & $15(57.6 \%)$ & $7(58.3 \%)$ & $5(41.6 \%)$ & $\begin{array}{l}3 \\
0\end{array}$ & 0.36 \\
\hline 6 & PP & I feel my patient's death is a professional failure. & $3(11.5 \%)$ & $23(88.5 \%)$ & - & $12(100 \%)$ & $\frac{5}{2}$ & 0.22 \\
\hline 11 & PP & $\begin{array}{l}\text { I wouldn't like to attend the terminal episode of a } \\
\text { patient of my specialty. }\end{array}$ & $1(3.8 \%)$ & $25(95.1 \%)$ & $2(16.6 \%)$ & $10(83.3 \%)$ & $\stackrel{0}{\circ}$ & 0.17 \\
\hline 12 & $\mathrm{PP}$ & $\begin{array}{l}\text { I can't help thinking about my family when facing a } \\
\text { patient who is going to die. }\end{array}$ & $11(42.3 \%)$ & $15(57.6 \%)$ & $8(66.6 \%)$ & $4(33.3 \%)$ & $\frac{0}{\circ}$ & 0.16 \\
\hline 19 & PP & $\begin{array}{l}\text { When I look after a terminal patient I use to think } \\
\text { about my own death. }\end{array}$ & $2(7.6 \%)$ & $24(92.3 \%)$ & $5(41.6 \%)$ & $7(58.3 \%)$ & $\frac{1}{\mathrm{U}}$ & 0.01 \\
\hline 20 & PP & Facing the family of a dying patient touches me. & $21(80.7 \%)$ & $5(19.2 \%)$ & $9(75 \%)$ & $3(25 \%)$ & 인 & 0.60 \\
\hline 26 & PP & $\begin{array}{l}\text { The highest sense of my job is to save the patient's } \\
\text { life. }\end{array}$ & $17(65.3 \%)$ & $9(34.6 \%)$ & $8(66.6 \%)$ & $4(33.3 \%)$ & $\stackrel{\oplus}{\stackrel{0}{0}}$ & 0.90 \\
\hline 30 & PP & $\begin{array}{l}\text { Frequent contact with death has made me seeing it } \\
\text { as something natural. }\end{array}$ & $21(80.7 \%)$ & $5(19.2 \%)$ & $11(91.6 \%)$ & $1(8.3 \%)$ & $\frac{\varepsilon}{\frac{c}{6}}$ & 0.39 \\
\hline 33 & PP & $\begin{array}{l}\text { I feel more comfortable if the request for assisting a } \\
\text { dying patient comes from his/her family. }\end{array}$ & $17(65.3 \%)$ & $9(34.6 \%)$ & $8(66.6 \%)$ & $4(33.3 \%)$ & $\frac{0}{3}$ & .90 \\
\hline 5 & $E$ & Death can be an exit to the burden of life. & $3(11.5 \%)$ & $23(88.5 \%)$ & $3(25 \%)$ & $9(75 \%)$ & $\frac{n}{\mp}$ & 0.29 \\
\hline 14 & $E$ & I think there is nothing else to see in this world. & - & $26(100 \%)$ & - & $12(100 \%)$ & 4 & 0.99 \\
\hline 15 & $E$ & I prefer dying than living without quality. & $15(57.6 \%)$ & $11(42.3 \%)$ & $4(33.3 \%)$ & $8(66.6 \%)$ & $\frac{\operatorname{ta}}{0}$ & 0.16 \\
\hline 21 & $E$ & I have thought it's no worth living. & $1(3.8 \%)$ & $25(96.1 \%)$ & - & $12(100 \%)$ & $\stackrel{0}{2}$ & 0.49 \\
\hline 31 & $E$ & There are moments when death can be a relief. & $20(76.9 \%)$ & $6(23.1 \%)$ & $10(83.3 \%)$ & $2(16.6 \%)$ & & 0.60 \\
\hline
\end{tabular}


Table 2. Results obtained for each item of the Attitude Toward Death Questionnaire by 38 physicians* (Continued)

\begin{tabular}{|c|c|c|c|c|c|c|c|c|}
\hline \multirow[t]{2}{*}{ Item } & \multirow[t]{2}{*}{ Dimension } & & \multicolumn{2}{|c|}{ Residents ( $n=26$ ) } & \multicolumn{2}{|c|}{ Staff $(n=12)$} & \multirow[b]{2}{*}{$\stackrel{\infty}{-}$} & \multirow[t]{2}{*}{ p } \\
\hline & & & Agree & Disagree & Agree & Disagree & & \\
\hline 3 & $\mathrm{~F}$ & $\begin{array}{l}\text { The possibility of my own death generates anxiety } \\
\text { in me. }\end{array}$ & $6(23.1 \%)$ & $20(76.9 \%)$ & $5(41.7 \%)$ & $7(58.3 \%)$ & $\frac{d}{2}$ & 0.24 \\
\hline 9 & $\mathrm{~F}$ & I feel disturbed when I think on how short life is. & $5(19.2 \%)$ & $21(80.8 \%)$ & - & $12(100 \%)$ & & 0.10 \\
\hline 13 & $\mathrm{~F}$ & I am afraid of dying young. & $3(11.5 \%)$ & $23(88.4 \%)$ & $4(33.3 \%)$ & $8(66.6 \%)$ & $\frac{2}{2}$ & 0.10 \\
\hline 24 & $\mathrm{~F}$ & I find it difficult to face death. & $8(30.7 \%)$ & $18(69.2 \%)$ & $3(25 \%)$ & $9(75 \%)$ & & 0.70 \\
\hline 28 & $\mathrm{~F}$ & $\begin{array}{l}\text { I think with fear about the possibility of contracting a } \\
\text { disease that drives me to death. }\end{array}$ & $12(46.1 \%)$ & $14(53.8 \%)$ & $6(50 \%)$ & $6(50 \%)$ & & 0.80 \\
\hline
\end{tabular}

*Department of Pediatrics, Specialty Hospital 25, Monterrey, Nuevo León.

Ac, acceptance; Av, avoidance; E, exit; F, fear; P, passage; PP, professional perspective.

access to special care, communication problems, false hopes of cure, ethical, religious and legal problems, inappropriate inclusion criteria, inadequate symptom assessment and management and, most important, health personnel lack of training. ${ }^{6}$

Different studies have shown that knowledge and skills reflected on the attitude towards death can be improved. Therefore, the first step is to identify the attitude of the personnel that works at Specialty Hospital 25 Pediatrics Department, whereby the Attitudes Toward Death (ATD) questionnaire was applied, which reveals each individual's posture..$^{20,22}$

In the training stages of a physician, attitude towards death is attributed to a failure in professional activity rather than to a natural, necessary phenomenon. Palliative medicine is not among health priorities in Mexico; in institutions there is considerable lack of knowledge about physical, psychological, social and spiritual needs of the end-stage patient and about those of his/her family; it is acknowledged that health professionals lack the necessary knowledge about palliative care, and as a result they have a negative attitude when confronted with patients' death.-9

In this study, 38 physicians did participate, including resident physicians who were on training for the pediatrics specialty and staff physicians of the pediatrics department. Staff physicians obtained higher scores than resident physicians, which reflects better attitude towards death; however, these averages were below the 141 points that are regarded as a positive attitude. When scores were analyzed by domain, there were no statistical differences between those obtained by residents and staff physicians.

Less than $20 \%$ of residents and staff physicians had a positive attitude towards death, which is not surprising, given that there is a training deficit, since the physician tends to see death as an enemy, and medical schools involuntarily reinforce this illusion. ${ }^{3}$ Physicians consider that their job is to fight against death, even knowing that it is unavoidable. For health professionals, especially for doctors, death constitutes a sensation of professional failure; they tend to feel guilty for not being able to cure their patients, and the terminal situation is understood as sign of impotence, many times unconsciously. The professional must learn that death is something natural. When he/she is able to accept it like this, he/she will dedicate him/herself to look after and comfort his/her patient until the end and without a sense of failure. . $^{9-11}$

In a study conducted by Hernández Cabrera, where the ATD questionnaire was applied to 50 family doctors, it became evident that attitudes in the study population showed certain ambiguity (directional ambivalence), together with some positive acceptance attitudes (especially at the cognitive level), predominance of avoidance attitudes, essentially nuanced by the affective content (fear). Most physicians didn't value death as a passage or transition to a better life, or as an exit to life problems, although a large part recognized that in certain moments it can be a relief of suffering.

The results of this study conducted in 38 pediatrics physicians indicate a significant difference between residents and staff physicians in one acceptance item that explores death as something unavoidable and in another avoidance item that talks about thinking about death, where residents are more reluctant to think about it, perhaps because they are younger and associate death with old age. There was also significant difference for item 19, which talks about thinking about one's own death when looking after a terminal patient; on this item, it is staff physicians who tend to think more about their own death than residents. However, ambiguity or directional ambivalence was notorious in the passage dimension, just as it was found in the study by Hernández Cabrera. ${ }^{22}$ 
In a study carried out by Leticia Ascencio Huertas at the National Cancer Institute of Mexico, the ATD questionnaire was applied to an oncological palliative care multidisciplinary team, which included physicians, psychologists and nurses; per-item percentages were identified that were very similar to those found in this study, and even ambiguity in the answers to the passage dimension was also evident, as this dimension addresses each individual's beliefs as regards life as a passage to another life. ${ }^{20}$

Helping patients to die peacefully is recognized as a task that is first of all human and deserving of praise, but it remains a medical objective of lower category than defeating death, and it is only admitted when the means to avoid it entirely fail. Death is not a failure of medical knowledge and practice, it cannot be indefinitely delayed, it is the natural and unavoidable end of existence that is going to affect us all. Medical great advances and discoveries will help to preserve health and prolong human life, but they will not be able to avoid that people continue dying. Health professionals should feel inclined both to investigate and treat the suffering that often accompanies the process of dying or the loss of a loved one and to look into factors and mechanisms that may help to prolong life. In a restructuring process of the concept and purposes of medicine, there are two goals, and both have the same category and importance: avoiding death when it is possible, and achieving for patients to live well until the end and to die peacefully, when the former is not possible. ${ }^{22}$

Education is an essential component in the process of developing a positive culture towards pediatric patients' death; therefore, health personnel needs to be trained in order to acquire a positive attitude, which will be reflected on high quality care for children and their families. ${ }^{1,2}$

\section{Conclusion}

1. Less than $20 \%$ of pediatric physicians have a positive attitude when confronted with death.
2. Most physicians didn't value death as a passage or transition to a better life, or as an exit to life's problems, although a large part of them recognized that in particular moments it can be a relief of suffering.

\section{References}

1. American Academy of Pediatrics. Committee on Bioethics and Committee on Hospital Care. Palliative care for children. Pediatrics. 2000;106(2 Pt 1):351-357.

2. Garduño-Espinoza A. Cuidados paliativos en niños. Atención a pacientes con enfermedad terminal. Acta Pediatr Mex. 2004;25:1-3.

3. Garduño-Espinoza A. Cuidados paliativos en el niño con enfermedad terminal. Dol Clin Ter. 2003;9(1);5-10.

4. Málishev-Krasnova M. El sentido de la muerte. Ciencia Ergo Sum. 2003;10(1):51-58.

5. Aries P. Historia de la muerte en occidente. Barcelona: El Acantilado; 2000.

6. Gómez-Sancho M. Morir con dignidad. Madrid: Arán Ediciones; 2005.

7. Gómez-Sancho R. Medicina paliativa en la cultura latina. Madrid: Arán Ediciones; 1999.

8. Gala-León FJ, Lupiani-Jiménez M, Raja-Hernández R, Guillén-Gestoso C, González-Infante JM, Villaverde-Gutiérrez MC, et al. Actitudes psicológicas ante la muerte y el duelo. Una revisión conceptual. Cuad Med Forense. 2002;30:39-50.

9. Fonnegra I. La muerte, el morir y el deudo desde diferentes perspectivas. Bogotá: Fundación Omega; 1992.

10. Hilden JM, Watterson J, Chrastek J. Tell the children. J Clin Oncol. 2000;18(17):3193-3195.

11. Hynson JL, Sawyer SM. Pediatric palliative care: distinctive needs and emerging issues. J Pediatr Child Health. 2001;37(4):323-325.

12. Blueband-Lagner M. The private lives of dying children. USA:Princeton University Press; 1978.

13. Kreicbergs U, Valdimarsdóttir U, Onelöv E, Björk O, Steineck G, Henter JI. Care-related distress: a nationwide study of parents who lost their child to cancer. J Clin Oncol. 2005;23(36):9162-9171.

14. Lannen PK, Wolfe J, Prigerson HG, Onelov E, Kreicbergs UC. Unresolved grief in a national sample of bereaved parents: impaired mental and physical health 4 to 9 years later. J Clin Oncol. 2008;26(36):5870-5876.

15. Davies B, Sehring SA, Partridge C, Cooper BA, Hughes A, Philp JC et al. Barriers to palliative care for children: perceptions of pediatric health care providers. Pediatrics. 2008;121(2):282.

16. Burns JP, Mitchell C, Griffith JL, Truog RD. End-of-life care in the pediatric intensive care unit: attitudes and practices of pediatric critical care physicians and nurses. Crit Care Med. 2001;29(3):658-664.

17. Khaneja S, Milrod B. Educational needs among pediatricians regarding caring for terminally ill children. Arch Pediatric Adolesc Med. 1998;152(9):909-914.

18. Pichardo-García LM, Diner K. La experiencia de la muerte y los cuidados paliativos. Una visión desde enfermería. An Med (Mex). 2010; 55(3):161-166.

19. Brockopp DY, King DB, Hamilton JE. The dying patient: a comparative study of nurse caregiver characteristics. Death Stud. 1991;15(3):245-258.

20. Ascencio-Huertas L, Allende-Pérez SR, Verastegui-Avilés E. Creencias, actitudes y ansiedad ante la muerte en un equipo multidisciplinario de cuidados paliativos oncológicos. Psicooncología. 2014;11(1):101-115.

21. Lara K, Ruiz N, Balcázar P. Ansiedad ante la muerte en adultos de población general y personal que trabaja en el sector salud. Revista Científica Electrónica de Psicología ICSa-UAEH. 2009;4:83-106.

22. Hernández-Cabrera G, González-García VM, Fernández-Machín L, Infante-Pereira O. Actitud ante la muerte en los médicos de la familia. Rev Cubana Med Gen Integr. 2002;18(1):22-32. 


\section{Appendix}

\section{Appendix 1. Attitudes Toward Death Questionnaire}

Av-avoidance, Ac-acceptance, F-fear, P-passage, E-exit, PP-professional perspective

$1 \mathrm{Av}$.

$2 \mathrm{Ac}$.

$3 F$.

4P.

$5 E$.

6PP.

$7 \mathrm{Ac}$.

8Av.

9F.

10P.

$11 \mathrm{PP}$.

12PP.

$13 \mathrm{~F}$.

14E.

$15 E$.

16 Ac.

$17 \mathrm{Av}$.

$18 \mathrm{P}$.

19PP.

20PP.

$21 E$.

22Av.

23Ac.

24F.

25P.

26PP.

$27 A c$.

28F.

$29 P$.

30PP.

$31 E$.

$32 A v$.

33PP.
Thinking about death is a waste of time.

Acceptance of death helps me to have more responsibility towards life.

The possibility of my own death generates anxiety in me.

I believe there is a better place in the afterlife.

Death can be an exit to life's burden.

I feel my patient's death is a professional failure.

My life has more meaning because I accept the fact of my own death.

I consider deliberately thinking about my own death to be morbid.

I feel disturbed when I think on how short life is.

I think I'll live after my death.

I wouldn't like to attend the terminal episode of a patient of my specialty.

I can't help thinking about my family when facing a patient who is going to die.

I am afraid of dying young.

I think there is nothing else to see in this world.

I prefer dying than living without quality.

I have thought about my death as an unavoidable fact.

I really prefer not thinking about death.

I see death as one step to eternity.

When I look after a terminal patient, I use to think about my own death.

Facing the family of a dying patient touches me.

I have thought it's no worth living.

I have thus far not thought about death as a real possibility.

Recognizing death as an unavoidable fact helps me in my personal growth.

I find it difficult to face death.

I expect life after death with pleasure.

The highest sense of my job is to save the patient's life.

I feel freer by accepting my death.

I think with fear about the possibility of contracting a disease that drives me to death

After death I will find happiness.

Frequent contact with death has made me seeing it as something natural.

There are moments when death can be a relief.

People should only think about death when they are old.

I feel more comfortable if the request for assisting a dying patient comes from his/herfamily. 